\title{
Diploma planned to revive science in UK schools
}

London. British post-16 secondary education is to undergo its biggest overhaul for 40 years following the government's decision to introduce a diploma similar to the French baccalauréat, while strengthening existing academic and vocational qualifications.

At the same time, the government has promised to review science and mathematics education, following a significant fall over the past decade in the proportion of 16- and 17-year-olds studying only mathematics and science. Fewer than 17 per cent of pupils aged 16 or more studied science and mathematics at Advanced (A) level last year, compared to 30 per cent in 1984.

There is also evidence of "insufficient" mathematical ability among science undergraduates. But the proportion of pupils achieving top grades has been steadily rising; 21 per cent of those taking physics A-level examinations last year achieved the highest grade, compared to 13.3 per cent in 1989 .

The plans have been recommended to the government by Sir Ron Dearing, who chaired a panel that carried out a 12-month inquiry into British education. They have been widely supported by representatives of industry, such as the Engineering Council and the Chemical Industries Association, which have long warned of the threat to Britain's industrial competitiveness posed by a poorly trained workforce.

The present vocational courses will be made more rigorous with the introduction of external assessment. The Advanced General National Vocational Qualification, the highest vocational qualification, will be renamed the 'Applied A-level'. These courses will be joined by a broader National Diploma, combining academic and vocational study in an attempt to stem the high drop-out rate from these courses.

The plans have been welcomed by the educational and scientific communities, but for a slightly different reason from that voiced by employers, namely that the proposals stop short of interfering with Alevel qualifications. These have formed the central plank of British further education for more than four decades and provide entry qualifications to university courses.

Although some people still consider Alevels to be the 'gold standard' of British education, others blame their relative narrowness - only two or three subjects are studied intensively over a two-year period as a major cause of underachievement.

Concern that A-level standards may slip in the future has led to the government considering 'toughening-up' humanities subjects in line with science, mathematics and foreign languages, which are considered more 'difficult' (see chart, right). The plans also include provision for the most able pupils to be "stretched" by studying degree-level courses while still at school.

"A-levels are a success story," says Carol Fitz-Gibbon, professor of education at the University of Durham, and author of a study suggesting that science is 'difficult' or 'severely graded' compared to other subjects. "They are a world class qualification. That's why we won so many Nobel prizes. But they are only for pupils at the top," she concedes. "Britain needs a vocational qualification that is equally well-respected."

Dick West, professor of education at the Open University, says the proposed new qualification is unlikely to be respected by

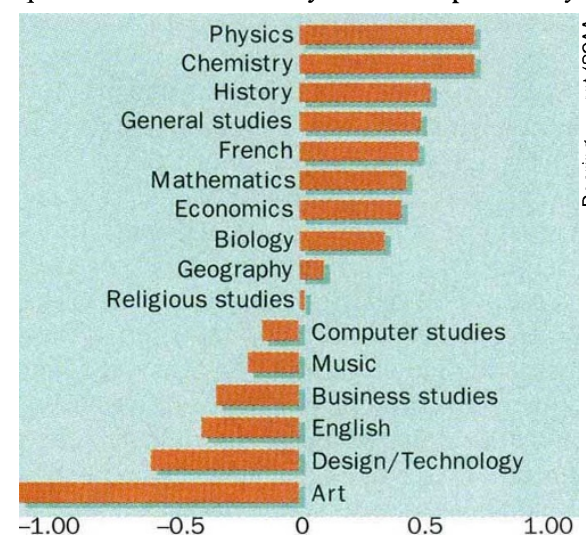

Degrees of difficulty: physics and chemistry were three-quarters of a grade more difficult than other subjects, according to an analysis of 1994 A-level results.

universities and employers while A-levels remain the 'gold standard'. "A-levels should have been abolished," he adds. West is among those who feel that the Dearing reforms " try to please everyone, but end up pleasing nobody".

West says he is unconvinced by Dearing's claim that fewer pupils study A-level mathematics and science because "society undervalues science". Mary Ratcliffe, chair elect of the Association for Science Education, says that poor science teaching, too, is one factor Dearing ought to have mentioned. The government, she says, has set a target of 1,000 science teachers to be trained by the end of this year. By February, only 86 places were filled.

Alan Smithers of Brunel University believes that the existing A-level curriculum works well for pupils intending to pursue careers in research. But he says it is of little practical relevance to the majority, who need to be "schooled in the nature and implications of science", but without the technical detail. "How relevant is an A-level in biology for a better understanding of the BSE crisis," he asks.

Ehsan Masood

\section{Neutrino observatory can go ahead after Canada cancels cut}

Ottawa. Intense lobbying by physicists in Canada and elsewhere has persuaded the Canadian federal government to reverse its decision, taken as part of a broad budget package last month, to end the support provided by Atomic Energy of Canada Limited (AECL) for the Sudbury Neutrino Observatory (SNO) Institute at the end of June (see Nature 380, 92; 1996).

Jon Gerrard, secretary of state for science, research and development, announced last week that AECL will continue to fund personnel attached to the project until construction is completed next January. Alternative sources of support will, however, still be needed to replace the individuals involved after the construction phase.

AECL has three scientists and several technicians working on the project, which has been planned to address the 'solar neutrino problem', and also provides some research facilities. These include neutron activation analysis used to detect small levels of uranium and thorium in construction materials.

Art McDonald, the director of the institute and professor of physics at Queen's University, stresses the important contribution of AECL's scientists to the project, whose funding comes from a broad spectrum of Canadian government and industry sources, as well as Britain's Particle Physics and Astronomy Research Council and the US Department of Energy.

If AECL had not been able to provide continued support, the project would have been in serious difficulties. One of those funded through AECL is the site project coordinator, Duncan Hepburn. "If we had lost him, we would have lost 50 per cent of our organization," says John Hykaway, a research associate in the physics department at Laurentian University. Hepburn has acted as a vital link between the project's many visiting physicists.

As to the international importance of the project, Hykaway reports that when the Nobel prize-winning physicist Hans Bethe recently celebrated his ninetieth birthday, a young scientist is said to have asked impertinently: "What are you hanging on for?" Bethe is said to have replied: "I'm waiting for the first data from the SNO."

According to Hykaway, the Sudbury project is the only one "that can really confirm whether neutrinos are flavourchanging", a process first invoked by Bethe and John Bahcall of Princeton University in New Jersey to explain the deficit, relative to theoretical expectations, of neutrinos that are observed to come from the Sun.

David Spurgeon 